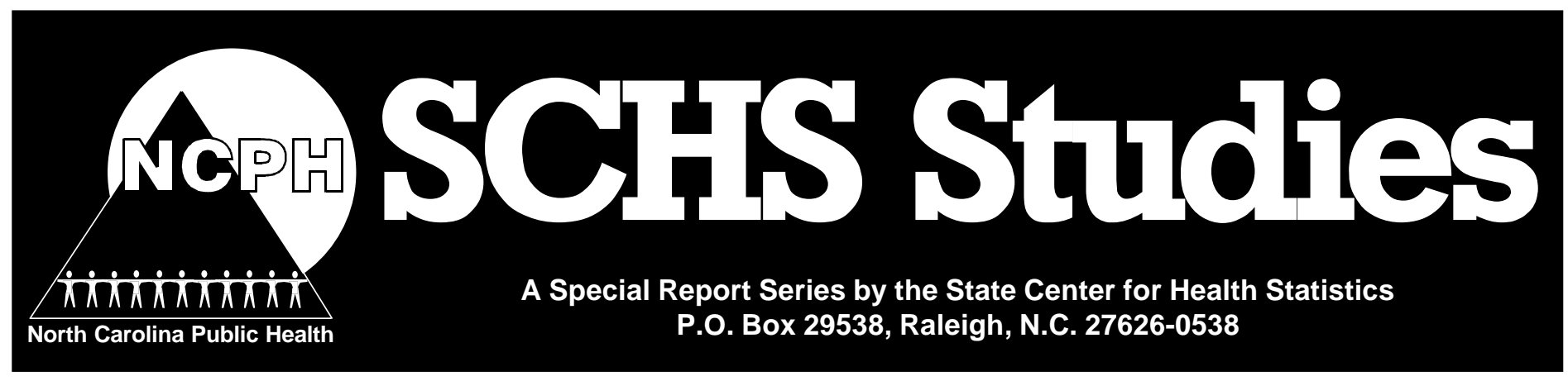

No. 113

www.schs.state.nc.us/SCHS

March 1999

\title{
Childhood Asthma in North Carolina
}

\author{
by \\ Paul Buescher \\ and \\ Kathleen Jones-Vessey
}

\begin{abstract}
Objectives: Asthma is one of the most common illnesses among children, yet there is little reliable information on the number of children in North Carolina who are living with asthma. This study examines the prevalence of asthma among children on Medicaid and the rates of hospitalization for asthma among all children in the state.

Methods: Claims paid by Medicaid during state fiscal year 1997-1998 with a diagnosis of asthma or for a prescription drug used to treat asthma are examined to count the number of children ages 0-14 at the state and county level with asthma. Percentages of enrolled children with asthma are calculated, and the costs of asthma treatment are portrayed. Hospital discharge rates for the period 1995-1997, per 100,000 children ages 0-14, are presented at the state and county level.

Results: Approximately 13 percent of North Carolina children ages 0-14 on Medicaid had an indication of asthma. By age, the prevalence rates were: 17 percent for 0-4, 10 percent for 5-9, and 9 percent for 10-14. There were large variations in prevalence among counties in North Carolina. More than $\$ 23,000,000$ was paid by Medicaid during the fiscal year for asthma-related services for children ages 0-14. During 1995-1997 there was an average of more than 6,500 asthma-related hospitalizations per year among children, with a statewide rate of 436 discharges per 100,000 children ages 0-14. There were large variations in the hospital discharge rate by county of residence. In contrast to some other studies, asthma prevalence and hospitalization rates were found to be higher in rural than in urban areas of North Carolina.

Conclusions: Many children on Medicaid in North Carolina have asthma and asthma is one of the most frequent causes of hospitalization among all children in the state. State administrative databases are useful for studying asthma and other conditions among children in North Carolina. Relying on existing data systems allows quick updates of the information at the state and county level, enhancing the ability to study trends in illness and hospitalization over time.
\end{abstract}




\section{Introduction}

Asthma is one of the most common illnesses of adults and children. Currently there is little reliable information on the number of people in North Carolina who are living with asthma. In 1997, 150 North Carolinians died with asthma listed on the death certificate as the primary cause of death. All but five of these persons were ages 25 and older. Although asthma is rarely reported as a primary cause of death among children, it is a common condition with serious consequences such as hospitalization and increased medical care costs. National data indicate that the prevalence of asthma and the rate of hospitalization among children have increased in recent years. ${ }^{1,2,3}$

Proper medical management is thought to reduce the morbidity and lost school days associated with asthma. Because of the high potential for preventing asthmarelated problems among children, the North Carolina Childhood Asthma Initiative was established in 1998 by the State Health Director. There are four work groups of the Childhood Asthma Initiative: epidemiology, education, environment, and medical management. This report begins to address the epidemiology of childhood asthma in North Carolina.

\section{Methods}

Two sources of data are used to estimate the prevalence of asthma among children in North Carolina: Medicaid paid claims data and hospital discharge data. Neither source will produce a reliable indication of the total prevalence of asthma among children. The Medicaid data indicates only those children diagnosed with asthma who received medical or prescription drug services. Other children on Medicaid with asthma may not have been diagnosed, or may not have had services paid for by Medicaid during the year. The hospital discharge data counts only those cases where the complications of asthma were serious enough to warrant one or more overnight hospital stays. Nevertheless, these data do provide estimates of the rate of serious cases of asthma among children in North Carolina.

For both types of data, ages 0-14 are used to estimate asthma in the childhood population. This age group is used by the National Center for Health Statistics for the Year 2000 objective for childhood asthma hospitalization rates. Estimates are provided for the state and for each county of residence. The Medicaid data are for claims paid during July 1997 through June 1998. The hospital discharge data are for calendar years 19951997 combined. Since hospitalization for asthma is a less common event, three years hospital discharge data are used to stabilize the county-level rates.

To define asthma prevalence in the Medicaid population, paid claims were selected where there was any mention of a diagnosis of asthma (ICD-9-CM code 493). Also, claims paid for drugs used for the treatment of asthma were selected. Asthma medications fall into two general categories: long-term control medications which are taken daily to achieve and maintain control of persistent asthma, and quick-relief medications which are taken to promptly reverse acute airflow obstruction. A pharmacist and a physician with the North Carolina Medicaid agency jointly selected the drug codes that were used. These drugs were determined by them to be highly specific for asthma. The claims with a diagnosis of asthma and the drug claims were then combined and unduplicated on Medicaid ID number within county of residence, so each child was counted only once. In the few cases where a child with asthma resided in more than one county during the year, he/she was counted once in each county. These counts of children with asthma were then divided by the number of children ages 0-14 in the county who were enrolled in Medicaid (and multiplied by 100), to get the percentages of children with asthma. The dollar value of the claims paid for these children for the drug and other asthma-related services were totaled for the state and each county, and an average amount paid by Medicaid per child for asthma services was calculated.

Hospital discharge records for 1995-1997 for children ages $0-14$ were selected if there was a primary or contributing diagnosis of asthma. The hospital discharge rates were computed as the number of asthma hospital discharges for the three years per 100,000 county residents ages $0-14$ for the three years. These are in effect average annual rates. There is no way to unduplicate the records in the hospital discharge file. Therefore, the rates indicate the number of asthma hospital episodes per 100,000 population, not the number of children hospitalized. A strength of the hospital discharge data is that it applies to the total population of children in North Carolina, not just children on Medicaid. A problem in producing county-level data is that only discharges from hospitals in North Carolina are 
included in the database. Therefore, counties on the border of North Carolina where many residents go to out-of-state hospitals will have asthma hospital discharge rates that are too low. Counties where this is likely to be a significant problem are: Camden, Caswell, Clay, Currituck, Dare, and Gates.

\section{Results}

During state fiscal year 1997-1998, more than 70,000 children in the Medicaid program ages 0-14 had a diagnosis of or used a prescription drug for asthma. This represented 13.3 percent of the total children ages 0 14 who were enrolled in Medicaid. The amount paid by Medicaid for asthma-related medical services and drugs during this year was more than $\$ 23,000,000$, or an average of $\$ 331$ per child with asthma. Table 1 shows this information by age group. More than half of the children ages 0-14 with asthma were under age 5 and the prevalence rate was highest in this age group $(17.3 \%)$. The prevalence rate decreases with age, though the average dollar amount per child expended by Medicaid for asthma-related services increases with age.

Table 2 presents the data by county of residence. Figure 1 is a county map of the prevalence of asthma (as measured here) among children on Medicaid. It can be seen that the prevalence is generally higher in the rural eastern and western counties of North Carolina. The prevalence rate in the ten most urban counties in
North Carolina is 11.7 percent, compared to a rate of 14.2 percent in the remaining more rural counties of the state. This is in contrast to some other studies that have found the prevalence of childhood asthma to be higher in urban areas., ${ }^{4,5} 6$ Figure 2 shows the counties with a Medicaid asthma prevalence rate higher than the state average of 13.3 percent.

Of the approximately 70,000 children ages $0-14$ on Medicaid who were identified with asthma, more than 63,000 or 90 percent were using one or more asthma prescription drugs paid for by Medicaid during the year. There was very little variation in this percentage across the three age groups: $0-4,5-9$, and 10-14. Thus, it appears that the large majority of these children with asthma are receiving some treatment with prescription drugs for their condition. The appropriateness of the treatment cannot be determined without a more detailed analysis of the drug claims. ${ }^{5,7}$ It should be mentioned that the dollar amounts paid for asthma-related services are probably less than would be found in other populations, since Medicaid generally pays a smaller proportion of the amount charged by providers than other third-party payers.

During 1995-1997, there were 19,584 hospitalizations of North Carolina children ages 0-14 where asthma was mentioned as the primary or a contributing cause of admission. This was an average of more than 6,500 asthma-related hospitalizations per year in this age group. The average annual hospital discharge rate

Table 1

State Fiscal Year 1998 North Carolina Medicaid Claims for Asthma*, Ages 0 to 14

\begin{tabular}{|c|c|c|c|c|c|}
\hline $\begin{array}{l}\text { Age } \\
\text { Group }\end{array}$ & $\begin{array}{l}\text { Total Number } \\
\text { of Medicaid } \\
\text { Asthmatic } \\
\text { Children* }\end{array}$ & $\begin{array}{l}\text { Total Number } \\
\text { of Medicaid- } \\
\text { Enrolled } \\
\text { Children }\end{array}$ & $\begin{array}{c}\text { Percent of } \\
\text { Medicaid } \\
\text { Enrollees with } \\
\text { Asthma Claims }\end{array}$ & $\begin{array}{c}\text { Total } \\
\text { Amount } \\
\text { Expended }\end{array}$ & $\begin{array}{c}\text { Average } \\
\text { Amount } \\
\text { Expended per } \\
\text { Asthmatic Child }\end{array}$ \\
\hline State Total & 70,218 & 528,621 & $13.3 \%$ & $\$ 23,245,239$ & $\$ 331$ \\
\hline 0 to 4 & 42,058 & 242,837 & $17.3 \%$ & $\$ 12,391,250$ & $\$ 295$ \\
\hline 5 to 9 & 17,386 & 170,646 & $10.2 \%$ & $\$ 6,369,366$ & $\$ 366$ \\
\hline 10 to 14 & 10,774 & 115,138 & $9.4 \%$ & $\$ 4,484,623$ & $\$ 416$ \\
\hline
\end{tabular}

${ }^{*}$ Represents an unduplicated count of paid Medicaid claims from $7 / 1 / 97$ to $6 / 30 / 98$ with any diagnosis of asthma (ICD-9CM=493) or a drug prescribed for asthmatics. 


\begin{tabular}{|c|c|c|c|c|c|}
\hline \multicolumn{6}{|c|}{$\begin{array}{c}\text { Table } 2 \\
\text { State Fiscal Year } 1998 \text { North Carolina Medicaid Claims for Asthma*, Children Ages } 0 \text { to } 14\end{array}$} \\
\hline $\begin{array}{l}\text { County of } \\
\text { Residence }\end{array}$ & $\begin{array}{l}\text { Total Number } \\
\text { of Medicaid } \\
\text { Asthmatic } \\
\text { Children* }\end{array}$ & $\begin{array}{l}\text { Total Number } \\
\text { of Medicaid- } \\
\text { Enrolled } \\
\text { Children }\end{array}$ & $\begin{array}{c}\text { Percent of } \\
\text { Medicaid } \\
\text { Enrollees with } \\
\text { Asthma Claims }\end{array}$ & $\begin{array}{l}\text { Total } \\
\text { Amount } \\
\text { Expended }\end{array}$ & $\begin{array}{c}\text { Average } \\
\text { Amount } \\
\text { Expended per } \\
\text { Asthmatic Child }\end{array}$ \\
\hline State Total & 70,218 & 528,621 & $13.3 \%$ & $\$ 23,245,239$ & $\$ 331$ \\
\hline Alamance & 891 & 6,255 & $14.2 \%$ & $\$ 366,599$ & $\$ 411$ \\
\hline Alexander & 249 & 1,828 & $13.6 \%$ & $\$ 105,650$ & $\$ 424$ \\
\hline Alleghany & 74 & 566 & $13.1 \%$ & $\$ 14,544$ & $\$ 197$ \\
\hline Anson & 345 & 2,929 & $11.8 \%$ & $\$ 157,386$ & $\$ 456$ \\
\hline Ashe & 173 & 1,603 & $10.8 \%$ & $\$ 28,443$ & $\$ 164$ \\
\hline Avery & 135 & 1,016 & $13.3 \%$ & $\$ 34,871$ & $\$ 258$ \\
\hline Beaufort & 565 & 4,059 & $13.9 \%$ & $\$ 217,866$ & $\$ 386$ \\
\hline Bertie & 427 & 2,645 & $16.1 \%$ & $\$ 102,621$ & $\$ 240$ \\
\hline Bladen & 432 & 3,545 & $12.2 \%$ & $\$ 395,955$ & $\$ 917$ \\
\hline Brunswick & 712 & 5,595 & $12.7 \%$ & $\$ 191,603$ & $\$ 269$ \\
\hline Buncombe & 1,626 & 12,608 & $12.9 \%$ & $\$ 515,632$ & $\$ 317$ \\
\hline Burke & 599 & 5,699 & $10.5 \%$ & $\$ 132,535$ & $\$ 221$ \\
\hline Cabarrus & 839 & 5,904 & $14.2 \%$ & $\$ 214,665$ & $\$ 256$ \\
\hline Caldwell & 728 & 4,884 & $14.9 \%$ & $\$ 193,196$ & $\$ 265$ \\
\hline Camden & 63 & 383 & $16.4 \%$ & $\$ 30,687$ & $\$ 487$ \\
\hline Carteret & 659 & 3,493 & $18.9 \%$ & $\$ 105,470$ & $\$ 160$ \\
\hline Caswell & 171 & 1,499 & $11.4 \%$ & $\$ 28,654$ & $\$ 168$ \\
\hline Catawba & 843 & 8,328 & $10.1 \%$ & $\$ 174,518$ & $\$ 207$ \\
\hline Chatham & 235 & 2,195 & $10.7 \%$ & $\$ 81,211$ & $\$ 346$ \\
\hline Cherokee & 642 & 1,983 & $32.4 \%$ & $\$ 97,079$ & $\$ 151$ \\
\hline Chowan & 146 & 1,500 & $9.7 \%$ & $\$ 34,979$ & $\$ 240$ \\
\hline Clay & 151 & 492 & $30.7 \%$ & $\$ 18,590$ & $\$ 123$ \\
\hline Cleveland & 901 & 7,410 & $12.2 \%$ & $\$ 138,248$ & $\$ 153$ \\
\hline Columbus & 1,233 & 6,385 & $19.3 \%$ & $\$ 462,648$ & $\$ 375$ \\
\hline Craven & 1,089 & 6,396 & $17.0 \%$ & $\$ 291,106$ & $\$ 267$ \\
\hline Cumberland & 2,765 & 23,533 & $11.7 \%$ & $\$ 1,293,612$ & $\$ 468$ \\
\hline Currituck & 163 & 1,108 & $14.7 \%$ & $\$ 27,927$ & $\$ 171$ \\
\hline Dare & 167 & 1,307 & $12.8 \%$ & $\$ 32,088$ & $\$ 192$ \\
\hline Davidson & 1,073 & 8,696 & $12.3 \%$ & $\$ 255,268$ & $\$ 238$ \\
\hline Davie & 132 & 1,453 & $9.1 \%$ & $\$ 44,488$ & $\$ 337$ \\
\hline Duplin & 576 & 4,233 & $13.6 \%$ & $\$ 115,248$ & $\$ 200$ \\
\hline Durham & 1,853 & 14,876 & $12.5 \%$ & $\$ 1,424,015$ & $\$ 768$ \\
\hline Edgecombe & 878 & 7,885 & $11.1 \%$ & $\$ 303,016$ & $\$ 345$ \\
\hline Forsyth & 1,687 & 17,713 & $9.5 \%$ & $\$ 838,971$ & $\$ 497$ \\
\hline Franklin & 393 & 3,215 & $12.2 \%$ & $\$ 137,908$ & $\$ 351$ \\
\hline Gaston & 1,274 & 12,722 & $10.0 \%$ & $\$ 422,571$ & $\$ 332$ \\
\hline Gates & 76 & 693 & $11.0 \%$ & $\$ 36,572$ & $\$ 481$ \\
\hline Graham & 151 & 650 & $23.2 \%$ & $\$ 35,659$ & $\$ 236$ \\
\hline Granville & 348 & 2,866 & $12.1 \%$ & $\$ 112,395$ & $\$ 323$ \\
\hline Greene & 199 & 1,692 & $11.8 \%$ & $\$ 58,507$ & $\$ 294$ \\
\hline Guilford & 3,232 & 25,359 & $12.7 \%$ & $\$ 993,081$ & $\$ 307$ \\
\hline Halifax & 936 & 7,148 & $13.1 \%$ & $\$ 270,391$ & $\$ 289$ \\
\hline Harnett & 871 & 6,998 & $12.4 \%$ & $\$ 304,527$ & $\$ 350$ \\
\hline Haywood & 563 & 3,477 & $16.2 \%$ & $\$ 183,261$ & $\$ 326$ \\
\hline Henderson & 568 & 5,181 & $11.0 \%$ & $\$ 165,437$ & $\$ 291$ \\
\hline Hertford & 379 & 2,892 & $13.1 \%$ & $\$ 182,289$ & $\$ 481$ \\
\hline Hoke & 420 & 3,255 & $12.9 \%$ & $\$ 132,720$ & $\$ 316$ \\
\hline Hyde & 75 & 502 & $14.9 \%$ & $\$ 22,234$ & $\$ 296$ \\
\hline Iredell & 810 & 6,444 & $12.6 \%$ & $\$ 393,913$ & $\$ 486$ \\
\hline Jackson & 501 & 2,123 & $23.6 \%$ & $\$ 106,109$ & $\$ 212$ \\
\hline
\end{tabular}




\begin{tabular}{|c|c|c|c|c|c|}
\hline \multicolumn{6}{|c|}{$\begin{array}{c}\text { Table } 2 \\
\text { State Fiscal Year } 1998 \text { North Carolina Medicaid Claims for Asthma*, Children Ages } 0 \text { to } 14\end{array}$} \\
\hline $\begin{array}{l}\text { County of } \\
\text { Residence }\end{array}$ & $\begin{array}{l}\text { Total Number } \\
\text { of Medicaid } \\
\text { Asthmatic } \\
\text { Children* }^{*}\end{array}$ & $\begin{array}{l}\text { Total Number } \\
\text { of Medicaid- } \\
\text { Enrolled } \\
\text { Children }\end{array}$ & $\begin{array}{c}\text { Percent of } \\
\text { Medicaid } \\
\text { Enrollees with } \\
\text { Asthma Claims }\end{array}$ & $\begin{array}{l}\text { Total } \\
\text { Amount } \\
\text { Expended }\end{array}$ & $\begin{array}{c}\text { Average } \\
\text { Amount } \\
\text { Expended per } \\
\text { Asthmatic Child }\end{array}$ \\
\hline Johnston & 1,081 & 7,367 & $14.7 \%$ & $\$ 406,342$ & $\$ 376$ \\
\hline Jones & 182 & 885 & $20.6 \%$ & $\$ 40,195$ & $\$ 221$ \\
\hline Lee & 426 & 4,065 & $10.5 \%$ & $\$ 94,161$ & $\$ 221$ \\
\hline Lenoir & 1,094 & 6,250 & $17.5 \%$ & $\$ 409,850$ & $\$ 375$ \\
\hline Lincoln & 427 & 3,286 & $13.0 \%$ & $\$ 76,888$ & $\$ 180$ \\
\hline Macon & 272 & 1,839 & $14.8 \%$ & $\$ 41,977$ & $\$ 154$ \\
\hline Madison & 153 & 1,320 & $11.6 \%$ & $\$ 24,014$ & $\$ 157$ \\
\hline Martin & 466 & 2,632 & $17.7 \%$ & $\$ 107,421$ & $\$ 231$ \\
\hline McDowell & 358 & 2,674 & $13.4 \%$ & $\$ 87,631$ & $\$ 245$ \\
\hline Mecklenburg & 3,374 & 36,314 & $9.3 \%$ & $\$ 754,604$ & $\$ 224$ \\
\hline Mitchell & 71 & 814 & $8.7 \%$ & $\$ 17,782$ & $\$ 250$ \\
\hline Montgomery & 271 & 2,257 & $12.0 \%$ & $\$ 45,894$ & $\$ 169$ \\
\hline Moore & 758 & 4,390 & $17.3 \%$ & $\$ 231,184$ & $\$ 305$ \\
\hline Nash & 792 & 6,474 & $12.2 \%$ & $\$ 237,402$ & $\$ 300$ \\
\hline New Hanover & 1,606 & 9,774 & $16.4 \%$ & $\$ 486,300$ & $\$ 303$ \\
\hline Northampton & 363 & 2,640 & $13.8 \%$ & $\$ 124,255$ & $\$ 342$ \\
\hline Onslow & 1,525 & 8,914 & $17.1 \%$ & $\$ 370,180$ & $\$ 243$ \\
\hline Orange & 349 & 3,500 & $10.0 \%$ & $\$ 160,634$ & $\$ 460$ \\
\hline Pamlico & 171 & 969 & $17.6 \%$ & $\$ 36,566$ & $\$ 214$ \\
\hline Pasquotank & 533 & 3,358 & $15.9 \%$ & $\$ 167,953$ & $\$ 315$ \\
\hline Pender & 470 & 3,240 & $14.5 \%$ & $\$ 99,596$ & $\$ 212$ \\
\hline Perquimans & 116 & 1,075 & $10.8 \%$ & $\$ 40,015$ & $\$ 345$ \\
\hline Person & 286 & 2,179 & $13.1 \%$ & $\$ 180,348$ & $\$ 631$ \\
\hline Pitt & 1,355 & 10,514 & $12.9 \%$ & $\$ 786,891$ & $\$ 581$ \\
\hline Polk & 82 & 841 & $9.8 \%$ & $\$ 13,278$ & $\$ 162$ \\
\hline Randolph & 1,292 & 7,417 & $17.4 \%$ & $\$ 277,507$ & $\$ 215$ \\
\hline Richmond & 750 & 5,122 & $14.6 \%$ & $\$ 285,097$ & $\$ 380$ \\
\hline Robeson & 2,666 & 16,055 & $16.6 \%$ & $\$ 1,115,099$ & $\$ 418$ \\
\hline Rockingham & 913 & 5,907 & $15.5 \%$ & $\$ 329,112$ & $\$ 360$ \\
\hline Rowan & 1,227 & 8,540 & $14.4 \%$ & $\$ 255,875$ & $\$ 209$ \\
\hline Rutherford & 481 & 4,294 & $11.2 \%$ & $\$ 60,448$ & $\$ 126$ \\
\hline Sampson & 692 & 5,144 & $13.5 \%$ & $\$ 204,969$ & $\$ 296$ \\
\hline Scotland & 647 & 4,468 & $14.5 \%$ & $\$ 220,205$ & $\$ 340$ \\
\hline Stanly & 560 & 3,694 & $15.2 \%$ & $\$ 111,345$ & $\$ 199$ \\
\hline Stokes & 198 & 2,291 & $8.6 \%$ & $\$ 51,416$ & $\$ 260$ \\
\hline Surry & 555 & 3,953 & $14.0 \%$ & $\$ 158,899$ & $\$ 286$ \\
\hline Swain & 267 & 1,180 & $22.6 \%$ & $\$ 62,156$ & $\$ 233$ \\
\hline Transylvania & 222 & 1,819 & $12.2 \%$ & $\$ 46,410$ & $\$ 209$ \\
\hline Tyrrell & 57 & 412 & $13.8 \%$ & $\$ 16,052$ & $\$ 282$ \\
\hline Union & 903 & 6,071 & $14.9 \%$ & $\$ 269,698$ & $\$ 299$ \\
\hline Vance & 739 & 5,345 & $13.8 \%$ & $\$ 319,124$ & $\$ 432$ \\
\hline Wake & 3,214 & 24,739 & $13.0 \%$ & $\$ 995,930$ & $\$ 310$ \\
\hline Warren & 273 & 1,997 & $13.7 \%$ & $\$ 77,705$ & $\$ 285$ \\
\hline Washington & 169 & 1,684 & $10.0 \%$ & $\$ 69,603$ & $\$ 412$ \\
\hline Watauga & 223 & 1,496 & $14.9 \%$ & $\$ 52,615$ & $\$ 236$ \\
\hline Wayne & 1,750 & 9,620 & $18.2 \%$ & $\$ 669,685$ & $\$ 383$ \\
\hline Wilkes & 791 & 4,252 & $18.6 \%$ & $\$ 195,476$ & $\$ 247$ \\
\hline Wilson & 767 & 7,283 & $10.5 \%$ & $\$ 203,291$ & $\$ 265$ \\
\hline Yadkin & 160 & 1,914 & $8.4 \%$ & $\$ 115,213$ & $\$ 720$ \\
\hline Yancey & 103 & 1,132 & $9.1 \%$ & $\$ 13,981$ & $\$ 136$ \\
\hline
\end{tabular}


Figure 1

State Fiscal Year 1997-98 Percent of North Carolina Medicaid Enrollees with Paid Claims for Asthma, Ages 0 to 14

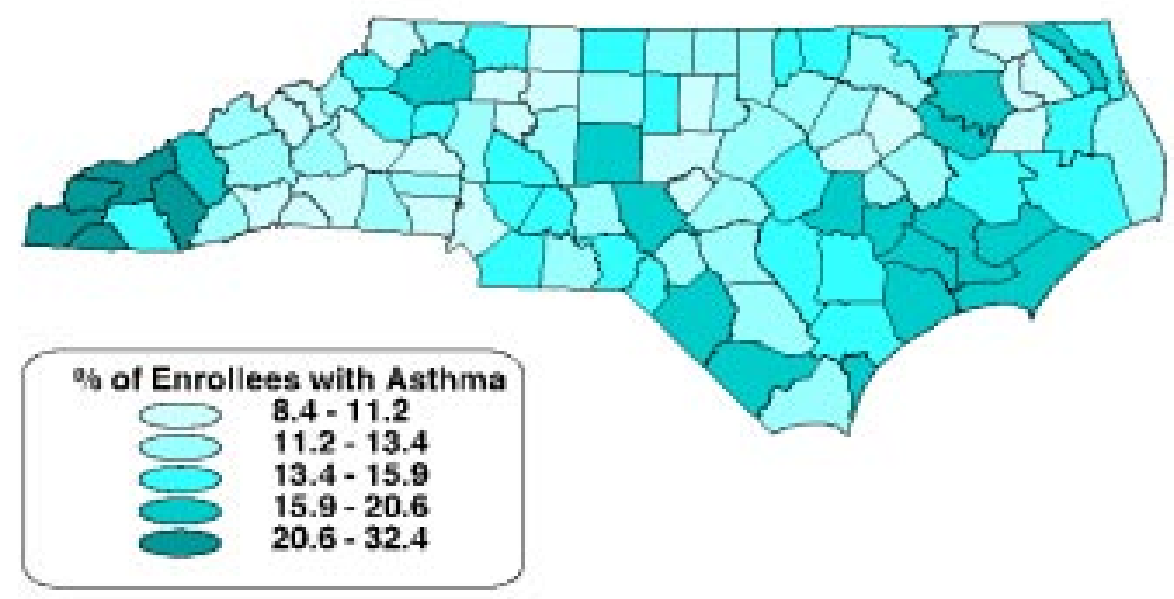

Figure 2

State Fiscal Year 1997-98 Percent of North Carolina Medicaid Enrollees with Paid Claims for Asthma, Ages 0 to 14

(Compared with $13.3 \%$ for the State)

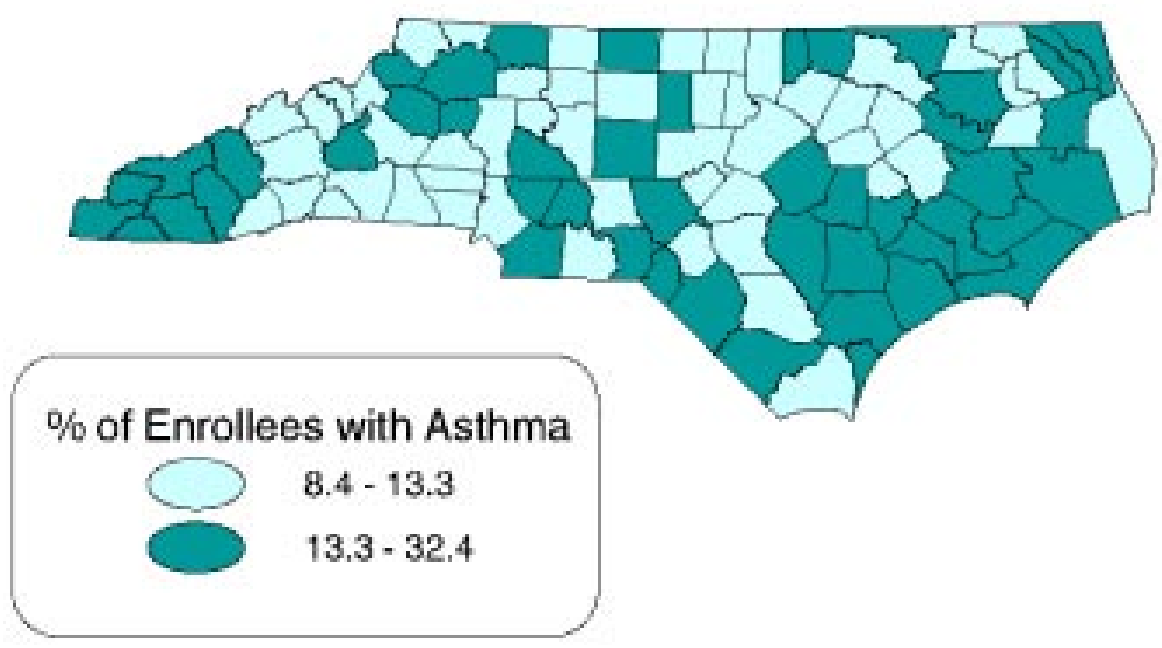


was 435.9 discharges per 100,000 children ages 0-14. Table 3 shows this information by age group. Again, the highest rate is in the youngest age group. Table 4 presents the data by county of residence. (Note that the population is three years added together.) Figure 3 is a map of the county hospital discharge rates, which shows the same general pattern as Figure 1 of elevated rates in the rural counties. The hospital discharge rate in the ten most urban counties of the state was 380.5 , compared to a rate of 475.0 in the remaining more rural counties. Figure 4 shows the counties with an asthma hospital discharge rate for children higher than the state average of 435.9 .

The asthma hospital discharge rate during 1995-1997 was 2.5 times as high for minority children in North Carolina (who are predominantly African American) as for white children. Much of this difference is due to socioeconomic and environmental risks for asthma being more prevalent in the minority population. ${ }^{8,9}$

The national Year 2000 Objective for the asthma hospital discharge rate for ages 0-14 is 225 per 100,000 population. This national goal is based on a primary diagnosis of asthma only, and thus is not comparable to the rates presented above. The 1995 United States asthma hospital discharge rate for children ages 0-14 was 369 , while the comparable rate for North Carolina for 1995-1996 was 264. Therefore, the rate for North Carolina is substantially lower than the national average, but still above the Year 2000 Health Objective.

Excluding normal newborn diagnoses, asthma is the most common primary diagnosis among North Carolina children ages 0-14 who were hospitalized, accounting for nearly 8 percent of all hospitalizations of children in this age group during 1995-1997.

\section{Discussion}

The data presented here show that more than 13 percent of children ages 0-14 on Medicaid in North Carolina in fiscal year 1997-1998 had a diagnosis of or used a prescription drug for asthma. There were large variations among the counties in North Carolina. For children ages 0-4 the statewide figure was more than 17 percent. These are probably minimum levels of asthma prevalence among children on Medicaid in North Carolina, since a substantial number of cases are likely to be undiagnosed or untreated. On the other hand, among

\begin{tabular}{|c|c|c|}
\hline \multicolumn{3}{|c|}{ 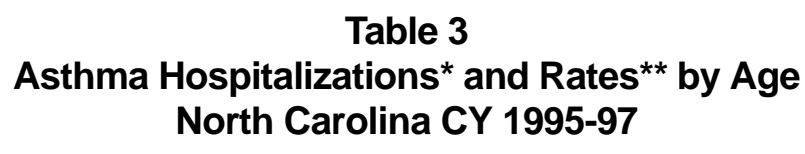 } \\
\hline $\begin{array}{l}\text { Age } \\
\text { Group } \\
0 \text { to } 4 \\
5 \text { to } 9 \\
10 \text { to } 14\end{array}$ & $\begin{array}{c}\text { Total } \\
\text { Discharges } \\
11,646 \\
5,057 \\
2,881\end{array}$ & $\begin{array}{l}\text { Rate } \\
765.9 \\
327.1 \\
202.1\end{array}$ \\
\hline Total 0 to 14 & 19,584 & 435.9 \\
\hline \multicolumn{3}{|c|}{$\begin{array}{l}\text { *Represents Hospitalizations with Any Mentioned Diagnosis } \\
\text { ICD-9-CM }=493 \text {. } \\
\text { **Rates are per } 100,000 \text { population. }\end{array}$} \\
\hline
\end{tabular}

children under age 5, a definitive diagnosis of asthma is more difficult, and so some children in this age group with asthma-like conditions may have been improperly diagnosed as having asthma.

In Mecklenburg County, North Carolina a large number of Medicaid patients were enrolled in HMOs during 1998. HMOs are paid on a capitated basis for these patients, and do not generally submit claims to be paid for individual services. Thus, the data in Table 2 for Mecklenburg County may understate the true figures, especially the amounts expended in the last two columns of the table. However, in Mecklenburg County the prescription drugs are still paid on a fee-for-service basis, so the drug claims will be included in our paid claims data file. Since about 90 percent of the asthma patients are identified through drug claims, the prevalence rate for Mecklenburg County may be a reasonably good estimate.

Though deaths of children from asthma are rare, many children are hospitalized each year in North Carolina due to complications of asthma. Minority children have a much higher rate of hospitalization from asthma than white children, and some counties in the state have an asthma hospitalization rate for children that is more than twice the state average.

The data on asthma prevalence among children on Medicaid and the data on childhood hospitalization for asthma both show rates to be higher in rural areas of North Carolina. This is in contrast to many other studies that have shown higher rates in urban areas. 


\begin{tabular}{|c|c|c|c|c|c|c|c|}
\hline \multirow[b]{3}{*}{ State Total } & \multicolumn{6}{|c|}{$\begin{array}{c}\text { Table } 4 \\
\begin{array}{c}\text { 1995-97 North Carolina Resident Asthma Hospitalizations* and Rates } \\
\text { by County of Residence, Children Ages } 0 \text { to } 14\end{array}\end{array}$} & \multirow{3}{*}{ Rate } \\
\hline & \multirow{2}{*}{$\begin{array}{l}\text { Number of } \\
\text { Hospitali- } \\
\text { zations } \\
19,584\end{array}$} & \multirow{2}{*}{$\begin{array}{l}\text { 3-Year } \\
\text { Population } \\
\text { Total } \\
4,492,358\end{array}$} & \multirow{2}{*}{$\begin{array}{l}\text { Rate } \\
435.9\end{array}$} & & \multirow[t]{2}{*}{$\begin{array}{l}\text { Number of } \\
\text { Hospitali- } \\
\text { zations }\end{array}$} & \multirow[t]{2}{*}{$\begin{array}{l}\text { 3-Year } \\
\text { Population } \\
\text { Total }\end{array}$} & \\
\hline & & & & & & & \\
\hline Alamance & 307 & 67,467 & 455.0 & Johnston & 369 & 62,196 & 593.3 \\
\hline Alexander & 99 & 17,671 & 560.2 & Jones & 34 & 6,016 & 565.2 \\
\hline Alleghany & 14 & 4,587 & 305.2 & Lee & 127 & 30,657 & 414.3 \\
\hline Anson & 187 & 14,842 & 1259.9 & Lenoir & 391 & 36,992 & 1057.0 \\
\hline Ashe & 40 & 10,916 & 366.4 & Lincoln & 138 & 35,002 & 394.3 \\
\hline Avery & 43 & 8,070 & 532.8 & McDowell & 70 & 21,015 & 333.1 \\
\hline Beaufort & 152 & 26,254 & 579.0 & Macon & 55 & 12,757 & 431.1 \\
\hline Bertie & 76 & 14,107 & 538.7 & Madison & 54 & 9,264 & 582.9 \\
\hline Bladen & 130 & 18,587 & 699.4 & Martin & 49 & 16,419 & 298.4 \\
\hline Brunswick & 97 & 34,486 & 281.3 & Mecklenburg & 1,245 & 383,942 & 324.3 \\
\hline Buncombe & 686 & 105,690 & 649.1 & Mitchell & 19 & 7,592 & 250.3 \\
\hline Burke & 154 & 47,582 & 323.7 & Montgomery & 48 & 15,513 & 309.4 \\
\hline Cabarrus & 372 & 69,902 & 532.2 & Moore & 178 & 37,452 & 475.3 \\
\hline Caldwell & 269 & 43,172 & 623.1 & Nash & 143 & 53,581 & 266.9 \\
\hline Camden & 16 & 3,553 & 450.3 & New Hanover & 217 & 80,121 & 270.8 \\
\hline Carteret & 76 & 30,843 & 246.4 & Northampton & 93 & 12,298 & 756.2 \\
\hline Caswell & 16 & 12,124 & 132.0 & Onslow & 412 & 106,057 & 388.5 \\
\hline Catawba & 174 & 75,604 & 230.2 & Orange & 115 & 52,001 & 221.2 \\
\hline Chatham & 44 & 25,271 & 174.1 & Pamlico & 13 & 6,504 & 199.9 \\
\hline Cherokee & 80 & 11,475 & 697.2 & Pasquotank & 135 & 23,490 & 574.7 \\
\hline Chowan & 30 & 9,188 & 326.5 & Pender & 59 & 21,776 & 270.9 \\
\hline Clay & 26 & 3,717 & 699.5 & Perquimans & 27 & 6,142 & 439.6 \\
\hline Cleveland & 127 & 55,005 & 230.9 & Person & 84 & 19,755 & 425.2 \\
\hline Columbus & 353 & 33,004 & 1069.6 & Pitt & 535 & 76,323 & 701.0 \\
\hline Craven & 255 & 57,702 & 441.9 & Polk & 17 & 7,748 & 219.4 \\
\hline Cumberland & 1,117 & 217,673 & 513.2 & Randolph & 315 & 73,127 & 430.8 \\
\hline Currituck & 17 & 9,932 & 171.2 & Richmond & 324 & 29,850 & 1085.4 \\
\hline Dare & 15 & 14,969 & 100.2 & Robeson & 677 & 83,557 & 810.2 \\
\hline Davidson & 249 & 82,751 & 300.9 & Rockingham & 195 & 51,934 & 375.5 \\
\hline Davie & 64 & 17,123 & 373.8 & Rowan & 449 & 73,527 & 610.7 \\
\hline Duplin & 101 & 28,098 & 359.5 & Rutherford & 39 & 35,644 & 109.4 \\
\hline Durham & 631 & 121,718 & 518.4 & Sampson & 131 & 32,069 & 408.5 \\
\hline Edgecombe & 203 & 39,847 & 509.5 & Scotland & 144 & 24,748 & 581.9 \\
\hline Forsyth & 591 & 171,172 & 345.3 & Stanly & 107 & 34,530 & 309.9 \\
\hline Franklin & 55 & 26,134 & 210.5 & Stokes & 39 & 24,425 & 159.7 \\
\hline Gaston & 349 & 114,785 & 304.1 & Surry & 120 & 36,566 & 328.2 \\
\hline Gates & 12 & 6,322 & 189.8 & Swain & 88 & 6,978 & 1261.1 \\
\hline Graham & 28 & 4,073 & 687.5 & Transylvania & 54 & 13,963 & 386.7 \\
\hline Granville & 96 & 25,654 & 374.2 & Tyrrell & 8 & 2,271 & 352.3 \\
\hline Greene & 70 & 9,953 & 703.3 & Union & 233 & 70,914 & 328.6 \\
\hline Guilford & 829 & 220,068 & 376.7 & Vance & 126 & 27,489 & 458.4 \\
\hline Halifax & 206 & 38,602 & 533.7 & Wake & 964 & 334,782 & 288.0 \\
\hline Harnett & 191 & 51,463 & 371.1 & Warren & 25 & 10,608 & 235.7 \\
\hline Haywood & 169 & 25,209 & 670.4 & Washington & 51 & 8,981 & 567.9 \\
\hline Henderson & 196 & 38,435 & 510.0 & Watauga & 69 & 16,332 & 422.5 \\
\hline Hertford & 134 & 14,752 & 908.4 & Wayne & 498 & 71,622 & 695.3 \\
\hline Hoke & 73 & 20,639 & 353.7 & Wilkes & 140 & 34,401 & 407.0 \\
\hline Hyde & 23 & 3,140 & 732.5 & Wilson & 235 & 43,647 & 538.4 \\
\hline Iredell & 476 & 64,693 & 735.8 & Yadkin & 78 & 19,474 & 400.5 \\
\hline Jackson & 110 & 13,820 & 796.0 & Yancey & 20 & 8,462 & 236.4 \\
\hline
\end{tabular}


Figure 3

1995-97 North Carolina Asthma Hospitalization Rates

State Residents Ages 0 to 14



$288-458.4$

$458.4-623.1$

$623.1-908.4$

$908.4-1261.1$

Figure 4

1995-97 North Carolina Asthma Hospitalization Rates

State Residents Ages 0 to 14

(Compared with State Rate of 435.9)

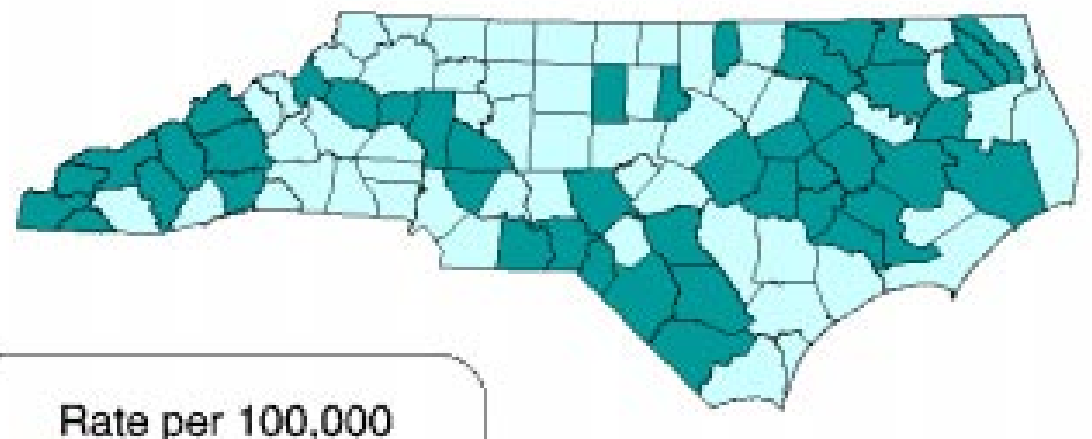

$100.2 \cdot 435.9$

$435.9-1261.1$ 
This study shows that existing state administrative databases can be used to portray the prevalence of asthma among children and the rates of hospitalization. These databases could also be used to measure asthma in the population of all ages. Special surveys to determine the prevalence of asthma among children, such as the International Study of Asthma and Allergies in Childhood (ISAAC), can produce valuable populationbased information. ${ }^{10}$ A pilot survey using the ISAAC protocol is being carried out in North Carolina and the resulting data will provide an important comparison to the results of the present study. But these surveys are fairly expensive and time-consuming to implement, and cannot feasibly be done regularly on a statewide basis. The state prevalence rates found here among North Carolina children on Medicaid are comparable to the prevalence rates of serious asthma found among children ages 13-14 in some ISAAC surveys, ${ }^{11,12}$ although very large variations in prevalence have been found from one country to another using the ISAAC protocol. ${ }^{10,13}$ Relying on existing state data systems allows quick and easy updates of the information, enhancing the ability to study trends in the prevalence of asthma over time.

\section{References}

1. Halfon N, Newacheck PW. Trends in the hospitalization for acute childhood asthma, 1970-84. Am J Public Health 1986; 76:1308-1311.

2. Asthma mortality and hospitalization among children and young adults - United States, 1980-1993. Morb Mortal Wkly Rep 1996; 45:350-353.

3. Goodman DC, Stukel TA, Chang CH. Trends in pediatric asthma hospitalization rates: regional and socioeconomic differences. Pediatrics 1998; 101:208-213.

4. Gergen PJ, Mullally DI, Evans R. National survey of prevalence of asthma among children in the United States, 1976 to 1980. Pediatrics 1988; 81:1-7.

5. Gerstman BB, Bosco LA, Tomita DK, Gross TP, Shaw MM. Prevalence and treatment of asthma in the Michigan Medicaid patient population younger than 45 years, 1980-1986. J Allergy Clin Immunol 1989; 83:1032-1039.
6. Burney PG. Asthma. Epidemiology. Br Med Bull 1992; 48:10-22.

7. Bosco LA, Gerstman BB, Tomita DK. Variations in the use of medication for the treatment of childhood asthma in the Michigan Medicaid population, 1980 to 1986 . Chest $1993 ; 104: 1727-1732$.

8. Wissow LS, Gittelsohn AM, Szklo M, Starfield B, Mussman M. Poverty, race, and hospitalization for childhood asthma. Am J Public Health 1988; 78:777-782.

9. Weitzman M, Gortmaker S, Sobol A. Racial, social, and environmental risks for childhood asthma. Am J Dis Child 1990; 144:1189-1194.

10. Worldwide variations in the prevalence of asthma symptoms: the International Study of Asthma and Allergies in Childhood (ISAAC). Eur Respir J 1998; 12:315-335.

11. Kaur B. Anderson HR, Austin J, Burr M, Harkins LS, Strachan DP, Warner JO. Prevalence of asthma symptoms, diagnosis, and treatment in 12-14 year old children across Great Britain (ISAAC UK). BMJ 1998; 316:118-124.

12. Pearce N, Weiland S, Keil U, Langridge P, Anderson HR, Strachan D, Bauman A, Young L, Gluyas P, Ruffin D, et al. Self-reported prevalence of asthma symptoms in children in Australia, England, Germany, and New Zealand: an international comparison using the ISAAC protocol. Eur Resp $J$ 1993; 6:1455-1461.

13. Pekkanen J, Remes ST, Husman T, Lindberg M, Kajosaari M, Koivikko A, Soininen L. Prevalence of asthma symptoms in video and written questionnaires among children in four regions of Finland. Eur Resp J 1997; 10:1787-1794. 




\author{
State of North Carolina \\ James B. Hunt Jr., Governor \\ Department of Health and Human Services \\ H. David Bruton, M.D., Secretary \\ State Health Director \\ A. Dennis McBride, M.D., M.P.H. \\ State Center for Health Statistics \\ John M. Booker, Ph.D., Director \\ www.schs.state.nc.us/SCHS
}

Department of Health and Human Services

State Center for Health Statistics

P. O. Box 29538

Raleigh, NC 27626-0538

919/733-4728

BULK RATE

U.S. Postage

PAID

Raleigh, NC 27626-0538

Permit No. 1862 